\title{
Alternative Activation of Macrophages in Mice Peritoneal Cavities and Diaphragms by Newborn Larvae of Trichinella spiralis
}

\author{
Nanase Itami,* Yoko Kondo,* Sayuri Tademoto, $†$ Daisuke Ito,* Soji Fukumoto $* \ddagger$ and Hitoshi Otsuki* \\ *Division of Medical Zoology, Department of Microbiology and Immunology, School of Medicine, Tottori University Faculty of \\ Medicine, Yonago 683-8503, Japan, †Technical Department, Tottori University, Yonago 683-8503, Japan, and $\$$ Tottori Medical Career \\ Support Center, Tottori University Hospital, Yonago 683-8504, Japan
}

\section{ABSTRACT}

Background Trichinellosis is a serious zoonosis with a worldwide distribution. Fecund adult worms in the intestine release newborn larvae (NBL) that enter the general circulation from 4 days post infection (dpi). Alternatively activated macrophages in the peritoneal cavities and the diaphragms in Trichinella spiralis infected mice have been reported. However, a role of newborn larvae is poorly understood.

Methods The total numbers of peritoneal macrophages in mice infected with 500 muscle-stage larvae were counted during early infection and then total RNA was extracted. Peritoneal macrophages from uninfected C57BL/6 mice were incubated with IL-4 or LPS as a control, or co-cultured with live NBL, and peritoneal macrophages were obtained from mice injected with live or frozen dead NBL into peritoneal cavity. Total RNA was extracted from these macrophages. Two types of gene expression, classical and alternative activation, were examined in the macrophages and diaphragms of the infected mice using semi-quantitative reverse transcription-PCR.

Results The number of peritoneal macrophages in T. spiralis infected mice increased significantly. mRNA peak expression of alternative activation markers, Ym1 and arginase-1 (Arg1), was confirmed in the peritoneal macrophages and in diaphragm of mice around $15 \mathrm{dpi}$, while mRNA expression of classical activation markers, $\mathrm{TNF} \alpha$, IP-10, and iNOS was not detected. Injection of live NBL into the peritoneal cavities induced mRNA expression of $\mathrm{Yml}$ and Arg1 in the peritoneal macrophages of mice 9 dpi. However, dead NBL did not induce such gene expression. Alternative activation was not detected in the peritoneal macrophages co-cultured with NBL in vitro.

Conclusion Gene expression of alternative activation makers, Ym1 and Arg1, was confirmed in the peritoneal macrophages and diaphragms of mice infected with T. spiralis. However, gene expression of classical activation markers was not detected. Live NBL induced an alternative activation of peritoneal macrophages in vivo, but not in vitro.
Key words alternative activation; gene expression; macrophage; semi-quantitative RT-PCR; Trichinella spiralis

Trichinellosis is a serious foodborne zoonotic disease with a worldwide distribution. ${ }^{1,2}$ A naïve host acquires infection with muscle-stage larvae (ML) of Trichinella spiralis, which invade host intestinal epithelial cells, where they develop into adults. Adult worms release newborn larvae (NBL) that enter the general circulation. ${ }^{3}$ Each larva invades a single myotube through several organs from 6 days post infection (dpi), and develop to $\mathrm{ML}$ in the skeletal muscle cell. Infected muscle cells are known as nurse cells, ${ }^{4}$ and they provide a long-term intracellular habitat for ML, which become infective to the next host within one month post infection.

Macrophages are the most ubiquitous types of cells in many organs and tissues. Macrophages serve as early detectors for invading pathogens through pattern recognition receptors, such as Toll-like receptors, and function as antigen-presenting cells which initiate host immune responses. Macrophages are equipped with receptors for the Thelper (Th) cell cytokines IFN- $\gamma$ and IL-4, and undergo specific activation programs during Th1 or Th2 immune responses. ${ }^{5}$ In a Th1 type environment, macrophages are classically activated by IFN- $\gamma$ and/or LPS. In classically activated macrophages, gene expression of inducible nitric oxide synthase (iNOS), TNF- $\alpha$ and IP-10 is observed, and they play a role as effector cells to kill pathogens. In a Th2 type environment, alternatively activated macrophages (AAMs) are induced by IL-4 or IL-13, and expressed arginase 1 (Arg1), FIZZ, and Ym1. ${ }^{6}$ The balance of the two distinct

Corresponding author: Hitoshi Otsuki, MD, PhD

otsuki@tottori-u.ac.jp

Received 2019 November 25

Accepted 2019 December 26

Online published 2020 January 24

Abbreviations: AAM, alternatively activated macrophage; Arg1, arginase 1; iNOS, inducible nitric oxide synthase; IP-10, interferon- $\gamma$-inducible protein 10; IL-4, interleukin-4; LPS, lipopolysacchride; ML, muscle-stage larvae; NBL, newborn larvae; RT, reverse transcription; STAT6, the signal transducer and activator of transcription; Th, T helper; T. spiralis, Trichinella spiralis; TNF $\alpha$, tumor necrosis factor $\alpha$ 
pathways of activation, iNOS and Arg1, is competitively regulated in the context of Th1- vs Th2-driven immune reactions. ${ }^{7}$ While newborn larvae of $T$. spiralis are sensitive to nitric oxide from classically activated macrophages, ${ }^{8}$ Th2 cytokines (IL-4 and IL-13) are important in expulsion of adult worm from mice intestines. ${ }^{9}$

Both interleukin (IL)-4 and IL-13 bind to the common receptor IL-4 $\alpha$, activating the signal transducer and activator of transcription (STAT) 6 signaling pathway. ${ }^{10}$ STAT6 directly promotes the expression of AAM signature genes, and it also augments AAM polarization indirectly, by binding to the promoter region of other transcription factors such as peroxisome proliferatoractivated receptor (PPAR) $\gamma$ and interferon regulatory factor (Irf) 4. Chitin promotes alternative activation via Jumonji domain containing-3 (Jmjd3)-mediated histone modification and expression of Irf4. ${ }^{11}$

AAMs are induced during the Th2 immune responses to several helminth parasites. ${ }^{12,13}$ AAMs represent important mediators of proper granuloma formation in the liver during schistosomiasis, and the lack of this response is lethal. ${ }^{14}$ Tissue-resident AAMs are induced in the peritoneal cavity by Heligmosoides polygyrus or in the thoracic cavity by Litomosoides sigmodontis, respectively. ${ }^{15}$

The gut is the initial site of parasitism where T. spiralis begins to influence the host's immune response. IL-4, IL-13, IL-4R $\alpha$-chain, and STAT6 are all important in worm expulsion during a primary infection of mice with $T$. spiralis. STAT6 signaling was found to be important for the type 2 cytokine production and intestinal mastocytosis in T. spiralis infected mice. ${ }^{9}$ Mast cell derived IL-4 and TNFa may regulate the induction of protective Th2 responses and intestinal inflammation associated with the expulsion of T. spiralis. ${ }^{16}$

Special attention has been given to the immune responses during the intestinal phase. Alternative activation of peritoneal macrophages in mice infected with T. spiralis was reported. ${ }^{17,}{ }^{18} \mathrm{We}$ found that the numbers of peritoneal macrophages were significantly increased at the early stage of $T$. spiralis infection, and confirmed the alternative activation of peritoneal macrophages. ${ }^{17,18}$ As some NBL were observed when we counted peritoneal cells, we examined the role of NBL in alternative activation of macrophages in the present study. Alternative activation was confirmed in diaphragm, ${ }^{8}$ and we examined the change in the expression levels of marker genes during the development process from NBL to ML in nurse cells.

\section{MATERIALS AND METHODS Rats and mice}

Male C57BL/6 mice and female Wister Rats were obtained from the Shimizu Laboratory Supply, Kyoto, Japan. All animals were maintained under specific pathogen-free conditions at the animal facility of Tottori University. Mice used were between 9-11 weeks old, and rats were 8-10 weeks old. This experiment was conducted at the animal study facility of the Tottori University Faculty of Medicine, and was approved by the Animal Experiment Ethical Committee of Tottori University. The approval number was 09-Y-13.

\section{Parasite}

T. spiralis (ISS413) was maintained by serial passage in male mice. ML were recovered from the muscle tissue of previously infected mice using artificial digestion with $1 \%$ pepsin in acidified water. ${ }^{19} \mathrm{C} 57 \mathrm{BL} / 6$ mice were orally inoculated with $500 \mathrm{ML}$ per mouse through a gastric canula.

NBL were obtained as described previously. ${ }^{20}$ Briefly, adult worms were recovered from washed intestines of Wister rats infected orally with 10,000 ML 6 days earlier. Adult worms were cultured for $24 \mathrm{~h}$ in RPMI containing $100 \mu \mathrm{g} / \mathrm{mL}$ streptomycin, $100 \mathrm{IU} / \mathrm{mL}$ penicillin, and $5 \%$ fetal calf serum (FCS) at $37{ }^{\circ} \mathrm{C}$ in an atmosphere of $5 \% \mathrm{CO}_{2}$. NBL were collected through nylon mesh. Some of the NBL were killed by freezing at $-20{ }^{\circ} \mathrm{C}$ to compare an effect on alternative activation of macrophages with live NBL.

\section{Preparation of peritoneal macrophages}

Mice were injected with $3 \mathrm{~mL}$ of $6 \%$ thioglycollate medium (Difco Laboratories, Detroit, MI), into peritoneal cavity. After four days, peritoneal macrophages were collected from uninfected C57BL/6 mice, using a micro-syringe and cold $6 \mathrm{~mL} \mathrm{PBS.}{ }^{21}$ Macrophages $(1 \times$ $10^{6}$ cells) were incubated in a $35 \mathrm{~mm}$ dish in the presence of $100 \mathrm{ng} / \mathrm{mL}$ lipopolysaccharide (LPS) or $20 \mathrm{ng} /$ mL IL-4 in DMEM with 5\% FCS for various times or days.

Peritoneal macrophages of mice infected with 500 ML were collected using a micro-syringe and cold 6 $\mathrm{mL}$ PBS at 0, 6, 9, 12, 15, 18, and 119 dpi. The cell pellets were obtained after centrifugation at 3,000 rpm for $5 \mathrm{~min}$. The total numbers of macrophages were counted and total RNA was extracted for semi-quantitative RTPCR with Isogen (Nippon Gene Co., Ltd., Tokyo, Japan) according to the manufacturer's instruction. 
Table 1. Gene-specific primers, length (bp), and cycle numbers used for semi-quantitative RT-PCR

\begin{tabular}{|c|c|c|c|c|c|c|}
\hline \multirow{2}{*}{ Gene name } & \multirow{2}{*}{ Primer sequences } & \multirow{2}{*}{$\begin{array}{l}\text { lengths } \\
\text { (bp) }\end{array}$} & \multirow{2}{*}{$\begin{array}{l}\text { Gene Bank } \\
\text { Accession No. }\end{array}$} & \multicolumn{3}{|c|}{ Cycle numbers of PCR } \\
\hline & & & & Mp 1 & Mp 2 & diaphragm \\
\hline Yml & $\begin{array}{l}\text { sense 5'- GAGCAAGACTTGCGTGACTATGAAGC -3' } \\
\text { anti-sense 5'- GACCACGGCACCTCCTAAATTGTTGTCC -3' }\end{array}$ & 867 & NM_009892 & 27 & 24 & 30 \\
\hline Arg1 & $\begin{array}{l}\text { sense 5'- GAAAGGCCCTGCAGCACTGAGGAAAGC -3' } \\
\text { anti-sense 5'- GGTAGCTGAAGGTCTCTTCCATCAC -3' }\end{array}$ & 581 & NM_007482 & 28 & 25 & 36 \\
\hline $\mathrm{TNF} \alpha$ & $\begin{array}{l}\text { sense 5'- CAGAAAGCATGATCCGCGACGTGGAAC -3' } \\
\text { anti-sense 5'- TCCAGGTCACTGTCCCAGCATCTTG -3' }\end{array}$ & 899 & NM_013693 & 26 & 26 & 40 \\
\hline IP-10 & $\begin{array}{l}\text { sense 5'- CCTATCCTGCCCACGTGTTGAG -3' } \\
\text { anti-sense 5'- CGCACCTCCACATAGCTTACAG -3' }\end{array}$ & 431 & NM_021274 & 26 & 26 & 40 \\
\hline iNOS & $\begin{array}{l}\text { sense 5'- AGCTCCTCACTGGGACAGCACAGAATG -3' } \\
\text { anti-sense 5'- ACCGGATGAGCTGTGAATTCCAGAG -3' }\end{array}$ & 624 & NM_010927 & 25 & 25 & 40 \\
\hline$\beta$ actin & $\begin{array}{l}\text { sense 5'- TGGAATCCTGTGGCATCCATGAAA -3' } \\
\text { anti-sense 5'- TAAACCGCAGCTCAGTAACAGTCC -3' }\end{array}$ & 349 & NM_007393 & 29 & 29 & 30 \\
\hline
\end{tabular}

Mp 1, Peritoneal macrophages of mice infected or injected with T. spiralis NBL; Mp 2, Thioglycollate elicited macrophage.

\section{Peritoneal macrophages from mice injected with NBL}

Live or frozen dead 10,000 NBL were injected into C57BL/6 mice peritoneal cavities and peritoneal macrophages were obtained from mice on $3,6,9$ or 30 dpi, and total RNA was extracted.

\section{Co-culture of peritoneal macrophages and NBL}

Peritoneal macrophages were collected from uninfected C57BL/6 mice, and $1 \times 10^{6}$ cells were co-cultured with 10,000 live NBL for 3 or 6 days in vitro. Total RNA was then extracted from the macrophages.

\section{Detection of ML after injection of NBL into the peri- toneal cavity}

NBL were injected into the peritoneal cavity of uninfected mice and ML burdens were assessed in whole carcasses using artificial digestion with $1 \%$ pepsin in acidified water.

\section{Total RNA from macrophages and diaphragms}

The macrophages were dissolved with Isogen and the diaphragms from uninfected and infected mice at 15 , $18,21,27$, and 30 dpi were homogenized in cold Isogen using Polytron homogenizer (Wheaton instruments, Nashville, NJ). Total RNA was extracted according to the manufacturer's instruction.

\section{Semi-quantitative RT-PCR}

Synthesis of cDNA was performed with $1 \mu \mathrm{g}$ of total RNA at $42{ }^{\circ} \mathrm{C}$ for 60 min using $2.5 \mu \mathrm{M}$ random primer (Takara Bio Inc, Kusatsu, Japan), $0.5 \mathrm{mM}$ dNTP and 1 $\mu \mathrm{L}$ M-MLV reverse transcriptase (Promega, Madison, WI) in $20 \mu \mathrm{L} 1 \mathrm{x}$ reaction buffer.

The reaction mixture of PCR contained $1 \mu \mathrm{M}$ of each primer, $0.2 \mathrm{mM}$ dNTP MIX, $1 \mathrm{U}$ Ex Taq DNA polymerase (Takara Bio Inc.) and $1.5 \mathrm{mM} \mathrm{MgCl}_{2}$ in a final volume of $25 \mu \mathrm{L}$. $\beta$-actin was used as an internal control. Primer sequences are shown in Table 1. The primers were chosen according to the BLAST tool that is available in GenBank database (https://www.ncbi. nlm.nih.gov/tools/primer-blast/index.cgi). The numbers of cycles for PCR were chosen to be linear range of amplification (Table 1). The PCR products were electrophoresed in $1.0 \%$ agarose gel and visualized with ethidium bromide using UV illumination.

\section{Statistical analysis}

Numbers of peritoneal macrophages were compared by one-way ANOVA test, implemented in Prism 7.0 (GraphPad Software, San Diego, CA).

\section{RESULTS}

Increase in peritoneal macrophages of $T$. spiralis infected mice

It was reported that mRNA expression of Ym1 and Arg 1 of peritoneal macrophages was gradually higher in T. spiralis infected mice than controls from 7 to $17 \mathrm{dpi} .{ }^{17}$ Then, we counted the number of peritoneal macrophages at first. The numbers of peritoneal macrophages of mice infected with $500 \mathrm{ML}$ increased 15 and 18 dpi significantly (Fig. 1). The peak number was 16,900 on 18 dpi. 


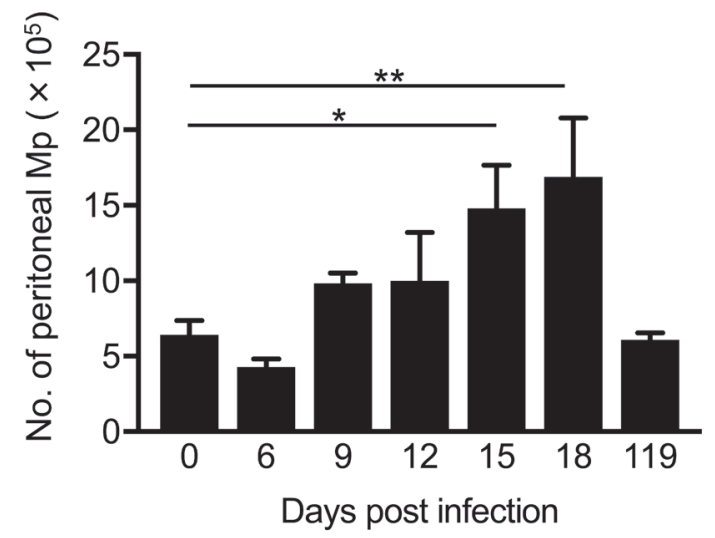

Fig. 1. Numbers of peritoneal macrophages in mice during early stage of $T$. spiralis infection. Peritoneal macrophages in C57BL/6 mice infected with $500 \mathrm{ML}$ were obtained and counted on 6, 9, $12,15,18$, and $30 \mathrm{dpi}$. Peritoneal macrophages in uninfected mice were also counted as a control. Each bar represents the mean \pm SD from three mice. $* P<0.05$ and $* *<0.01$.

\section{mRNA expression in peritoneal macrophages stim- ulated with LPS or IL-4 in vitro}

We obtained thioglycollate induced peritoneal macrophages from uninfected mice and confirmed gene expression of classically activated or alternatively activated macrophages stimulated with LPS or IL-4, respectively, ${ }^{5,12}$ by semi-quantitative RT-PCR to evaluate the phenotype of macrophages in T. spiralis infected mice. mRNA expression of TNF $\alpha$, IP-10, and iNOS was observed from $3 \mathrm{~h}$ to $24 \mathrm{~h}$ in LPS stimulated macrophages, while that of Ym1 and Arg1 was detected from 3 or $12 \mathrm{~h}$ to $72 \mathrm{~h}$ in IL-4-stimulated macrophages in vitro. Expression of these genes were not observed from $3 \mathrm{~h}$ to $72 \mathrm{~h}$ in vitro in thioglycollate elicited untreated (UT) macrophages (Fig. 2).

\section{Ym1 and Arg1 mRNA expression in peritoneal mac- rophages in $T$. spiralis infected mice}

Mice infected with ML showed a complete elimination of adult worms from their guts at $17 \mathrm{dpi}$, and the females produced the most NBL from 5 to 9 dpi. ${ }^{17} \mathrm{We}$ confirmed mRNA expression of alternative activation markers, Ym1 and Arg1, in macrophages from 6 to 18 dpi, and a peak expression was detected around $15 \mathrm{dpi}$. However, mRNA expression of TNF $\alpha$, IP-10, and iNOS was not observed in the peritoneal macrophages of T. spiralis infected mice (Fig. 3).

\section{Live NBL induce mRNA expression of Ym1 and Arg1 in peritoneal macrophages in vivo}

Adult worms of $T$. spiralis recovered from rat intestines were cultured for $24 \mathrm{~h}$, and NBL were collected. Live

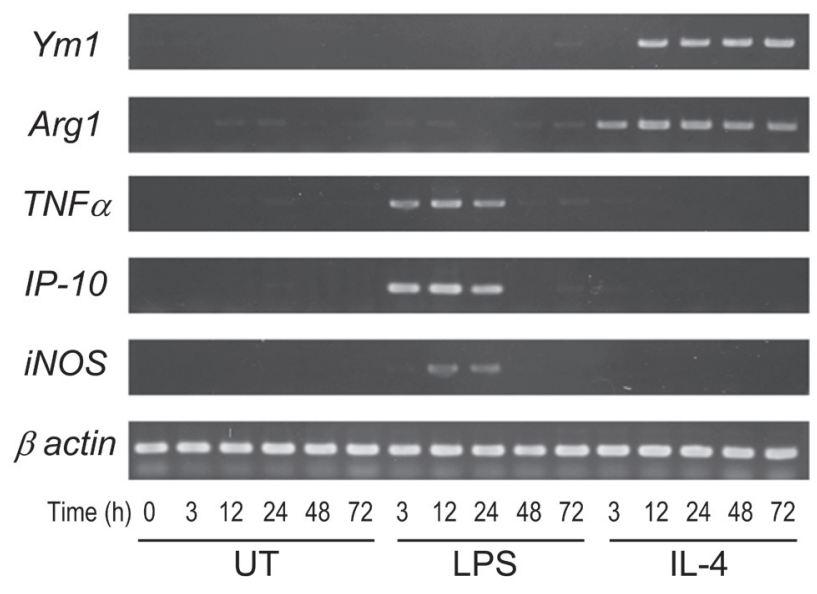

Fig. 2. LPS or IL-4 induced gene expression in peritoneal macrophages of uninfected mice. Thioglycollate elicited peritoneal macrophages were incubated with $100 \mathrm{ng} / \mathrm{mL}$ LPS or $20 \mathrm{ng} / \mathrm{mL}$ IL-4, or as untreated (UT) controls for 3-72 h. Total RNA was obtained from macrophages and gene expression was detected by semiquantitative RT-PCR using each primer set listed in Table 1. DNA fragments were separated in 1.0\% agarose gel electrophoresis, and were revealed with ethidium bromide in a transilluminator.

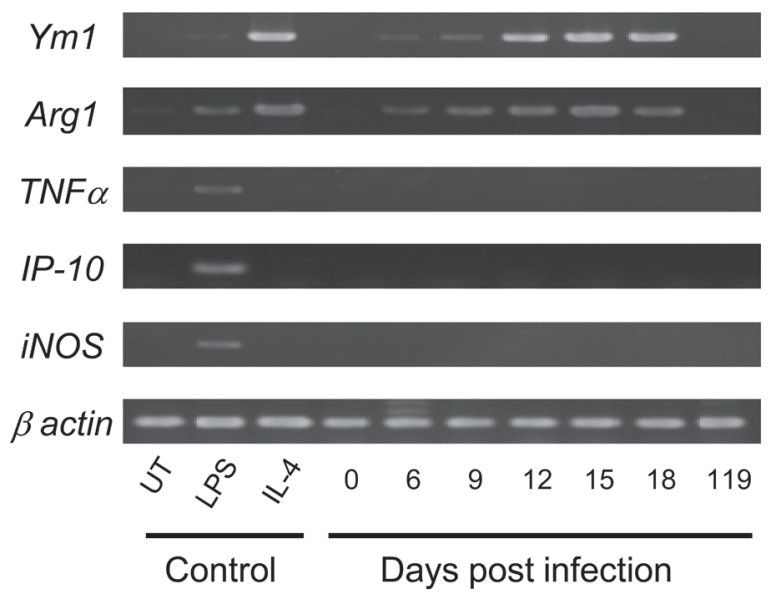

Fig. 3. Gene expression in peritoneal macrophages of T. spriralis infected mice. Peritoneal macrophages were obtained from mice infected with $500 \mathrm{ML}$ during early stage $(6,9,12,15$, and $18 \mathrm{dpi})$ and $119 \mathrm{dpi}$, and uninfected control mice ( 0 dpi). Thioglycollate elicited peritoneal macrophages were incubated with $100 \mathrm{ng} /$ $\mathrm{mL}$ LPS for $3 \mathrm{~h}$ or $20 \mathrm{ng} / \mathrm{mL} \mathrm{IL-4}$ for $24 \mathrm{~h}$ as positive controls. The gene expression of macrophages was detected by semiquantitative RT-PCR. DNA fragments were separated in $1.0 \%$ agarose gel electrophoresis, and were revealed with ethidium bromide in a transilluminator.

NBL were injected to the peritoneal cavities to examine whether alternative activation is induced in peritoneal macrophages without effect of adult worms. Live NBL induced mRNA expression of $\mathrm{Ym} 1$ in the peritoneal macrophages of mice $9 \mathrm{dpi}$, and also induced Arg1 


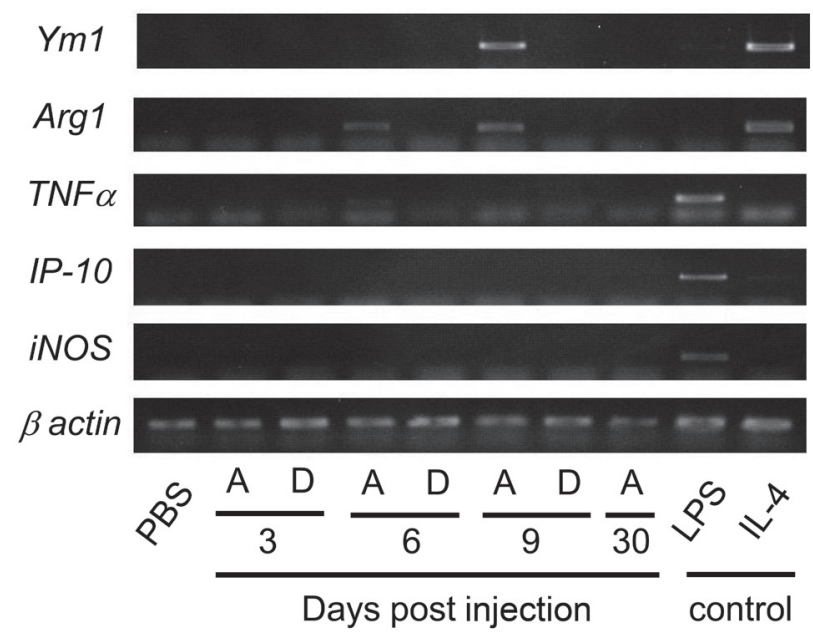

Fig. 4. Gene expression in peritoneal macrophages of mice injected with live or dead NBL of T. spiralis. Live (A) or frozen dead (D) 10,000 NBL were injected into the mice peritoneal cavities, and peritoneal macrophages were obtained from NBL injected-mice on 3, 6, 9, and 30 days post injection. Thioglycollate elicited peritoneal macrophages were incubated with $100 \mathrm{ng} / \mathrm{mL}$ LPS for 3 h, 20 ng/mL IL-4 or PBS for $24 \mathrm{~h}$ as controls. The gene expression of macrophages was detected by semi-quantitative RT-PCR. DNA fragments were separated in 1.0\% agarose gel electrophoresis, and were revealed with ethidium bromide in a transilluminator.

gene expression in mice 6 and 9 dpi. Then, dead NBL were also injected to peritoneal cavities to examine the possibility of alternative activation in the absence of excretory/secretory products of NBL and the stimuli in invasion into host tissues of NBL. Dead NBL did not induce any mRNA expression of Yml or Arg1 in macrophages (Fig. 4). Classically activated makers, TNF $\alpha$, IP-10, or iNOS, were not expressed in macrophages of NBL injected mice.

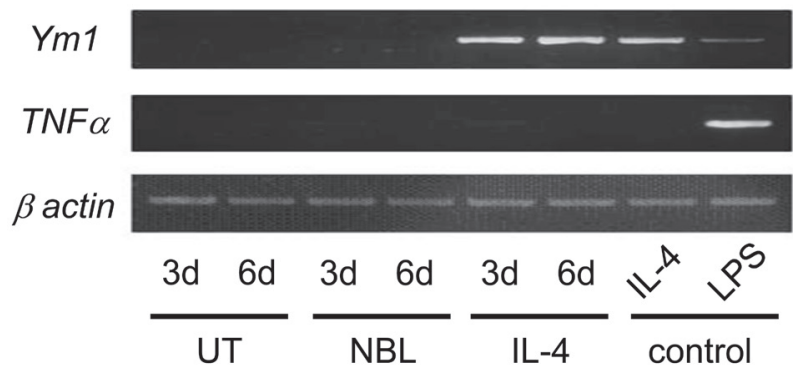

Fig. 5. Gene expression in peritoneal macrophages co-cultured with live NBL, IL-4 or LPS in vitro. Thioglycollate elicited peritoneal macrophages were cultured for 3 or 6 days (d) with live NBL or $20 \mathrm{ng} / \mathrm{mL}$ IL-4, or as untreated (UT) controls. The macrophages were incubated with $20 \mathrm{ng} / \mathrm{mL}$ IL-4 for 1 day or with $100 \mathrm{ng} / \mathrm{mL}$ LPS for $3 \mathrm{~h}$ as positive controls. The gene expression of macrophages was detected by semi-quantitative RT-PCR. DNA fragments were separated in 1.0\% agarose gel electrophoresis, and were revealed with ethidium bromide in a transilluminator.

\section{Live NBL did not induce mRNA expression of Ym 1 in peritoneal macrophages in vitro}

Live NBL were co-cultured with thioglycollate elicited peritoneal macrophages to examine that NBL directly or indirectly induce alternative activation. Yml or TNFa mRNA was not expressed in peritoneal macrophages co-cultured with live NBL for 3 or 6 days in vitro, while Ym1 mRNA was confirmed in macrophages incubated with IL-4 for 1, 3, or 6 days (Fig. 5). ${ }^{12}$

\section{mRNA expression of Ym1 and Arg1 in the dia- phragms of $T$. spiralis infected mice}

NBL invade a single myotube from 6 to 9 dpi, and develop to ML within 1 month in nurse cell surrounded collagen capsule. ${ }^{4}$ Alternative activation of macrophages in diaphragms of C57BL/6 mice 17 dpi was reported, ${ }^{8}$ and we confirmed Ym1 and Arg1 mRNA

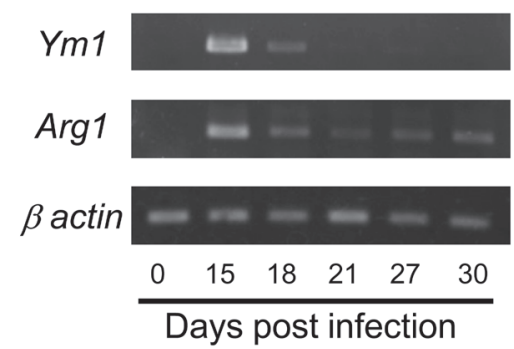

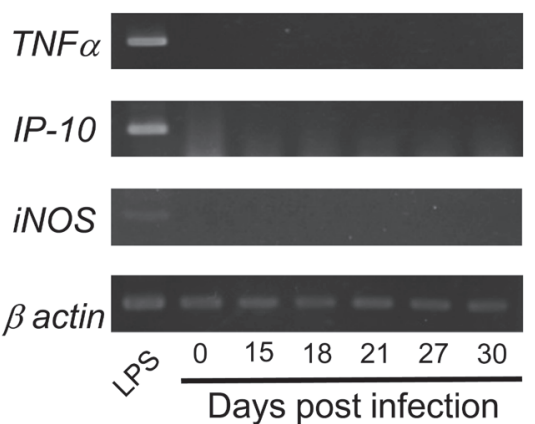

Fig. 6. Gene expression in the diaphragms of mice infected with T. spiralis ML. Total RNA of diaphragms of mice 0-30 dpi was obtained. Thioglycollate elicited peritoneal macrophages were incubated with $100 \mathrm{ng} / \mathrm{mL}$ LPS for $3 \mathrm{~h}$ as positive control. The gene expression in the diaphragms and macrophages was detected using semi-quantitative RT-PCR. DNA fragments were separated in $1.0 \%$ agarose gel electrophoresis, and revealed with ethidium bromide in a transilluminator. 
expression in the diaphragms of mice $15 \mathrm{dpi}^{8}$ We found that the expression levels seem to decrease during nurse cell formation. On the other hand, mRNA expression of TNF $\alpha$, IP-10, and iNOS was not observed in the diaphragms (Fig. 6).

\section{DISCUSSION}

Mice infected with high dose of ML showed a complete elimination of adult worms from their gut at $17 \mathrm{dpi}$, and the reproductive life span was from 5 to $9 \mathrm{dpi}$, which is the period when the females produced the most NBL. The reproductive capacity index, which means the total number of NBL/female worm, peaked on $7 \mathrm{dpi.} .^{17}$ The levels of Arg1, Ym1, and Fizzl mRNA expression in T. spiralis infected mice were gradually increased from 7 to 17 dpi. $^{17}$ We found a significant increase in peritoneal macrophages of mice infected with $T$. spiralis 15 and 18 dpi and we confirmed the alternative activation of peritoneal macrophages. ${ }^{17,} 18$ A peak of Ym1 and Arg1 mRNA expression seemed to be at 15 dpi in the present study. On the other hand, gene expression of TNF $\alpha$, IP-10, and iNOS was not detected, which suggested that Thl cytokine is almost absent in the peritoneal cavity.

It has been reported that excretory-secretory (ES) products $(5 \mu \mathrm{g} / \mathrm{mL})$ from 3 -day-old adult worms and 5 -day-old adult worms/NBL of T. spiralis inhibited iNOS gene expression in LPS stimulated J774A.1 macrophages, and can modulate macrophage function towards the alternative phenotype in vitro in the absence of Th2 cytokine. ${ }^{22}$ A T. spiralis specific $53 \mathrm{kDa}$ glycoprotein (TsP53) has been identified as a major component of its ES antigen. Incubation with recombinant TsP53 for $24 \mathrm{~h}$ up-regulated mRNA expression of the mannose receptor, Arg1, Ym1, and IL-10 in peritoneal macrophages derived from IL-4R $\alpha \mathrm{KO}$ and WT mice to similar levels, ${ }^{23}$ which means alternative activation of macrophages is independent of IL-4 and/or IL-13.

In the present study, we found that live NBL injected into mice peritoneal cavity in vivo induced mRNA expression of Ym1 and Arg1 in peritoneal macrophages, but dead NBL did not induce such gene expression. Live NBL co-cultured with peritoneal macrophages in vitro did not induce alternative activation of macrophages. It is supposed that alternative activation of the peritoneal macrophages of mice infected with T. spiralis might be independent of ES products of NBL or TsP35, and dependent of IL-4 and/or IL-13 secreted from host cells. In the process of purifying and counting peritoneal macrophages in $T$. spiralis infected mice, we detected some NBL in the peritoneal fluids. We then injected 10,000 NBL into the peritoneal cavity, and observed that $1.8 \%$ (40-413 NBL) develop into ML in mice 30 dpi. A higher percentage of NBL migrated to the peritoneal cavity in infected mice may reinvade the various muscles and developed to ML.

Arg1 activity was measured in the lung macrophages from rats during the early phase $(3,6,9,13 \mathrm{dpi})$ of $T$. spiralis infection, and a significant increase was observed only on $13 \mathrm{dpi}$, when the migratory phase was about to end in the murine model, compared with uninfected rats. ${ }^{24}$ Alternative activation of macrophages was reported in the diaphragms of $T$. spiralis infected mice at 17 dpi. ${ }^{8}$ We supposed the peak mRNA expression of Ym1 and Arg1 in the diaphragm of mouse at $15 \mathrm{dpi}$ and found that such gene expression in the diaphragms decreased during nurse cell formation, which suggested that the roles of alternative activation of macrophages were decreased, because collagen capsules surrounding nurse cells might protect larvae.

As we decided the cycle number of PCR for each gene, which expression levels were compared among some samples in a linear range, we could point out the profile in the alternative activation of macrophages. However, it is necessary to quantify the mRNA expression levels using real-time PCR in order to evaluate the accurate expression levels hereafter.

Chitinase, an enzyme that cleaves and breaks down the chitin found on fungi, worms, and organisms, has been implicated in $\mathrm{Th} 2$ immune responses during parasitic infections. Ym1, a chitinase family member, is a chitin-binding protein without chitinase activity, and is expressed by AAMs. ${ }^{11}$ Ym1 originally discovered as an eosinophil chemotactic factor, ${ }^{25}$ and may promote eosinophil accumulation in the parasite-infected tissues. ${ }^{11}$ The arrival of NBL in the muscle coincides with an intestinal Th2 immune response that expels adult worms and induces prominent blood and tissue eosinophilia. ${ }^{26}$ Although markers of AAMs were dramatically upregulated in the diaphragm tissues of eosinophil-ablated and WT mice, eosinophil-ablation was associated with a marked increase in iNOS transcription and decrease in M2 marker expression at $17 \mathrm{dpi}^{8}$ T. spiralis larvae are susceptible to direct killing by NO. Eosinophils support parasite growth and survival by promoting the accumulation of Th2 cells and preventing induction of iNOS in macrophages and neutrophils in the diaphragms. ${ }^{8}$

It is apparent that in contrast with the wellestablished role for Th2 immune responses in expulsion of intestinal worms, Th2 immune responses support both tissue-dwelling parasitic worms and the host. Arg1 expressed in AAM produce L-ornithine that can be metabolized into L-proline, which is essential for collagen synthesis and tissue repair and regeneration. ${ }^{27}$ 
Ym1 shares homology with chitinases, and has been associated with cellular recruitment and extra cellular matrix deposition during tissue repair. ${ }^{28}$ AAM plays an essential role in wound healing during helminth infection. ${ }^{29}$

Similar to mouse models, CD14+ blood monocytes from patients with asymptomatic filarial infection exhibited significantly diminished expression of iNOS and significantly enhanced expression of Arg1. Human filarial infection is associated with the presence of monocytes characterized by an alternatively activated phenotype. ${ }^{30}$ The immunological reaction in patients of trichinellosis is characterized by eosinophilia and a rather Th2-oriented cytokine profile. ${ }^{1}$ We suppose that alternatively activation of macrophages might be induced in humans infected with Trichinella. Th2 responses induced by $T$. spiralis modulate the progression of experimental colitis, ${ }^{18,} 31$ and type 1 diabetes, ${ }^{32}$ in mice models. By improving our understanding of functions of human AAMs and molecular aspects of cross-talk between host and parasite, new therapeutic approaches of autoimmune diseases are likely to be achieved.

Acknowledgments: This study was supported by a JSPS KAKENHI Grant-in-Aid (C), Grant Number 21590464.

The authors declare no conflict of interest.

\section{REFERENCES}

1 Gottstein B, Pozio E, Nöckler K. Epidemiology, diagnosis, treatment, and control of trichinellosis. Clin Microbiol Rev. 2009;22:127-45. DOI: 10.1128/CMR.00026-08, PMID: 19136437

2 Rostami A, Gamble HR, Dupouy-Camet J, Khazan H, Bruschi F. Meat sources of infection for outbreaks of human trichinellosis. Food Microbiol. 2017;64:65-71. DOI: 10.1016/ j.fm.2016.12.012, PMID: 28213036

3 Harley JP, Gallicchio V. Trichinella spiralis: migration of larvae in the rat. Exp Parasitol. 1971;30:11-21. DOI: 10.1016/0014-4894(71)90064-6, PMID: 5157122

4 Despommier DD. How does Trichinella spiralis make itself at home? Parasitol Today. 1998;14:318-23. DOI: 10.1016/S01694758(98)01287-3, PMID: 17040798

5 Martinez FO. Regulators of macrophage activation. Eur J Immunol. 2011;41:1531-4. DOI: 10.1002/eji.201141670, PMID: 21607943

6 Gordon S. Alternative activation of macrophages. Nat Rev Immunol. 2003;3:23-35. DOI: 10.1038/nri978, PMID: 12511873

7 Munder M, Eichmann K, Modolell M. Alternative metabolic states in murine macrophages reflected by the nitric oxide synthase/arginase balance: competitive regulation by CD4+ T cells correlates with Th1/Th2 phenotype. J Immunol. 1998;160:5347-54. PMID: 9605134
8 Gebreselassie NG, Moorhead AR, Fabre V, Gagliardo LF, Lee NA, Lee JJ, et al. Eosinophils preserve parasitic nematode larvae by regulating local immunity. J Immunol. 2012;188:417-25. DOI: 10.4049/jimmunol.1101980, PMID: 22131328

9 Urban JF Jr, Schopf L, Morris SC, Orekhova T, Madden KB, Betts CJ, et al. Stat6 signaling promotes protective immunity against Trichinella spiralis through a mast cell- and T celldependent mechanism. J Immunol. 2000;164:2046-52. DOI: 10.4049/jimmunol.164.4.2046, PMID: 10657657

10 Takeda K, Tanaka T, Shi W, Matsumoto M, Minami M, Kashiwamura S, et al. Essential role of Stat6 in IL-4 signalling. Nature. 1996;380:627-30. DOI: 10.1038/380627a0, PMID: 8602263

11 Jang J, Nair M. Alternatively activated macrophages revisited: new insights into the regulation of immunity, inflammation and metabolic function following parasite infection. Curr Immunol Rev. 2014;9:147-56. DOI: 10.2174/157339550966613 1210232548, PMID: 24772059

12 Nair MG, Cochrane DW, Allen JE. Macrophages in chronic type 2 inflammation have a novel phenotype characterized by the abundant expression of Yml and Fizzl that can be partly replicated in vitro. Immunol Lett. 2003;85:173-80. DOI: 10.1016/S0165-2478(02)00225-0, PMID: 12527225

13 Noël W, Raes G, Hassanzadeh Ghassabeh G, De Baetselier $\mathrm{P}$, Beschin A. Alternatively activated macrophages during parasite infections. Trends Parasitol. 2004;20:126-33. DOI: 10.1016/j.pt.2004.01.004, PMID: 15036034

14 Herbert DBR, Hölscher C, Mohrs M, Arendse B, Schwegmann A, Radwanska M, et al. Alternative macrophage activation is essential for survival during schistosomiasis and downmodulates T helper 1 responses and immunopathology. Immunity. 2004;20:623-35. DOI: 10.1016/ S1074-7613(04)00107-4, PMID: 15142530

15 Jenkins SJ, Ruckerl D, Thomas GD, Hewitson JP, Duncan $\mathrm{S}$, Brombacher F, et al. IL-4 directly signals tissue-resident macrophages to proliferate beyond homeostatic levels controlled by CSF-1. J Exp Med. 2013;210:2477-91. PMCID: PMC3804948. DOI: 10.1084/jem.20121999, PMID: 24101381

16 Ierna MX, Scales HE, Saunders KL, Lawrence CE. Mast cell production of IL-4 and TNF may be required for protective and pathological responses in gastrointestinal helminth infection. Mucosal Immunol. 2008;1:147-55. DOI: 10.1038/ mi.2007.16, PMID: 19079172

17 Ding J, Bai X, Wang XL, Wang YF, Shi HN, Rosenthal B, et al. Developmental profile of select immune cells in mice infected with Trichinella spiralis during the intestinal phase. Vet Parasitol. 2016;231:77-82. DOI: 10.1016/j.vetpar.2016.07.019, PMID: 27501987

18 Kang SA, Park MK, Park SK, Choi JH, Lee DI, Song SM, et al. Adoptive transfer of Trichinella spiralis-activated macrophages can ameliorate both Th1- and Th2-activated inflammation in murine models. Sci Rep. 2019;9:6547. DOI: 10.1038/s41598-019-43057-1, PMID: 31024043

19 Zarlenga DS, Boyd P, Lichtenfels JR, Hill D, Ray Gamble $\mathrm{H}$. Identification and characterisation of a cDNA sequence encoding a glutamic acid-rich protein specifically transcribed in Trichinella spiralis newborn larvae and recognised by infected swine serum. Int J Parasitol. 2002;32:1361-70. DOI: 10.1016/S0020-7519(02)00127-3, PMID: 12350371 
20 Beiting DP, Bliss SK, Schlafer DH, Roberts VL, Appleton JA. Interleukin-10 limits local and body cavity inflammation during infection with muscle-stage Trichinella spiralis. Infect Immun. 2004;72:3129-37. DOI: 10.1128/IAI.72.6.31293137.2004, PMID: 15155614

21 Fukumoto S, Hirai K, Tanihata T, Ohmori Y, Stuehr DJ, Hamilton TA. Excretory/secretory products from plerocercoids of Spirometra erinacei reduce iNOS and chemokine mRNA levels in peritoneal macrophages stimulated with cytokines and/or LPS. Parasite Immunol. 1997;19:325-35. DOI: 10.1046/j.1365-3024.1997.d01-215.x, PMID: 9278945

22 Bai X, Wu X, Wang X, Guan Z, Gao F, Yu J, et al. Regulation of cytokine expression in murine macrophages stimulated by excretory/secretory products from Trichinella spiralis in vitro. Mol Cell Biochem. 2012;360:79-88. DOI: 10.1007/s11010-0111046-4, PMID: 21909996

23 Du L, Wei H, Li L, Shan H, Yu Y, Wang Y, et al. Regulation of recombinant Trichinella spiralis $53-\mathrm{kDa}$ protein (rTsP53) on alternatively activated macrophages via STAT6 but not IL-4R $\alpha$ in vitro. Cell Immunol. 2014;288:1-7. DOI: 10.1016/ j.cellimm.2014.01.010, PMID: 24534206

24 Falduto GH, Vila CC, Saracino MP, Gentilini MV, Venturiello SM. Regulatory parameters of the lung immune response during the early phase of experimental trichinellosis. Vet Parasitol. 2016;231:47-52. DOI: 10.1016/j.vetpar.2016.05.009, PMID: 27211081

25 Owhashi M, Arita H, Hayai N. Identification of a novel eosinophil chemotactic cytokine (ECF-L) as a chitinase family protein. J Biol Chem. 2000;275:1279-86. DOI: 10.1074/ jbc.275.2.1279, PMID: 10625674
26 Fabre V, Beiting DP, Bliss SK, Gebreselassie NG, Gagliardo LF, Lee NA, et al. Eosinophil deficiency compromises parasite survival in chronic nematode infection. J Immunol. 2009;182:1577-83. DOI: 10.4049/jimmunol.182.3.1577, PMID: 19155506

27 Munder M. Arginase: an emerging key player in the mammalian immune system. Br J Pharmacol. 2009;158:638-51. DOI: 10.1111/j.1476-5381.2009.00291.x, PMID: 19764983

28 Faz-López B, Morales-Montor J, Terrazas LI. Role of macrophages in the repair process during the tissue migrating and resident helminth infections. BioMed Res Int. 2016;2016:111. Article ID 8634603. DOI: $10.1155 / 2016 / 8634603$, PMID: 27648452

29 Kreider T, Anthony RM, Urban JF Jr, Gause WC. Alternatively activated macrophages in helminth infections. Curr Opin Immunol. 2007;19:448-53. DOI: 10.1016/ j.coi.2007.07.002, PMID: 17702561

30 Babu S, Kumaraswami V, Nutman TB. Alternatively activated and immunoregulatory monocytes in human filarial infections. J Infect Dis. 2009;199:1827-37. DOI: 10.1086/599090, PMID: 19456233

31 Du L, Tang H, Ma Z, Xu J, Gao W, Chen J, et al. The protective effect of the recombinant $53-\mathrm{kDa}$ protein of Trichinella spiralis on experimental colitis in mice. Dig Dis Sci. 2011;56:2810-7. DOI: 10.1007/s10620-011-1689-8, PMID: 21476030

32 Saunders KA, Raine T, Cooke A, Lawrence CE. Inhibition of autoimmune type 1 diabetes by gastrointestinal helminth infection. Infect Immun. 2007;75:397-407. DOI: 10.1128/ IAI.00664-06, PMID: 17043101 